\section{Dosimetry in CBCT with Different Protocols: Emphasis on Small FOVs Including Exams for TMJ}

Helena Aguiar Ribeiro Nascimento ${ }^{1}$, Marcos Ely Almeida Andrade², Marco Antonio Gomes Frazão ${ }^{3}$, Eduarda Helena Leandro Nascimento ${ }^{1}$, Flavia Maria Moraes Ramos-Perez ${ }^{4}$, Deborah Queiroz Freitas ${ }^{1}$

\author{
'Department of Oral Diagnosis, \\ Division of Oral Radiology, \\ Piracicaba Dental School, \\ UNICAMP - Universidade de \\ Campinas, Piracicaba, SP, Brazil \\ ${ }^{2}$ Department of Nuclear Energy, \\ UFPE - Universidade Federal de \\ Pernambuco, Recife, PE, Brazil \\ ${ }^{3}$ Division of Oral Radiology, \\ FOR - Faculdade de Odntologia \\ de Recife, Recife, PE, Brazil \\ ${ }^{4}$ Department of Clinical and \\ Preventive Dentistry, School of \\ Dentistry, UFPE - Universidade Federal \\ de Pernambuco, Recife, PE, Brazil
}

Correspondence: Eduarda Helena Leandro Nascimento, Av. Limeira, 901, 13414-903 Piracicaba, SP, Brasil. Tel: +55-19-8294-6677. e-mail: eduarda.hln@gmail.com
This study aimed to estimate the absorbed dose in cone beam computed tomography (CBCT) exams according to different exposure parameters and size and position of the field of view (FOV). In addition was compared the absorbed dose of two smaller FOV scans with that of a larger FOV scan for evaluation of temporomandibular joint (TMJ), as it is a bilateral structure. CBCT scans were obtained on OP300 Maxio unit varying scanning mode (standard, high and endo) as well as size $(5 \times 5,6 \times 8$ and $8 \times 15 \mathrm{~cm})$ and positioning of FOV. With a small FOV, different areas were scanned (maxilla or mandible, anterior or posterior and TMJ). Absorbed doses were determined using thermoluminescent dosimeters on the skin surface of sensitive organs of an anthropomorphic phantom. Endo mode showed the highest dose, followed by the high and standard modes in all FOV positions. With small FOV, doses were higher in the posterior region, especially in the mandible. Dose reduction occurred when small FOVs were used, but it was not proportional to FOV size reduction. For TMJ, the dose in a single acquisition with large FOV was greater than two acquisitions with small FOV, but lower than two acquisitions with medium FOV (6x8 $\mathrm{cm})$. In conclusion, scanning mode, size and FOV position have great influence on the absorbed dose. Small FOV decreases the dose, but there is no linear relation between FOV size and dose. For bilateral exams of TMJ, double acquisition with small FOVs produces decrease in absorbed dose relative to a large FOV.
Key Words: cone-beam computed tomography, dosimetry, radiation exposure, temporomandibular joint.

\section{Introduction}

Since the first reports on the cone beam computed tomography (CBCT) to dentistry, which occurred in the late 1990s $(1,2)$, CBCT has become an integral part of the set of diagnostic tools for various dental specialties. The use of $\mathrm{CBCT}$ in oral and maxillofacial imaging has grown rapidly due to its low cost and high spatial resolution, but also because absorbed radiation dose is generally low compared with the multidetector CT (MDCT) (3). Nevertheless, the amount of radiation to which patients are exposed when subjected to a CBCT scan still remains a concern. That concern is justifiable in the head and neck imaging, since the irradiated field houses organs such as the thyroid, the salivary glands and the lens of the eyes (4).

Usually, the operator of a CBCT unit has several protocols available and selects the most appropriate setup according to the clinical requirements and the anatomical characteristics of the region of interest (ROI). As the radiation dose absorbed by the patient seems to depend primarily on the field of view (FOV) and on the exposure parameters, it is important to choose the protocol that provides the lowest dose to the patient while providing the necessary diagnostic information, according to the ALADA principle ("As low as diagnostically acceptable") $(5,6)$.
Some CBCT devices have medium and large FOVs that provide images of the entire head. However, in dental practice images of a single tooth or a few teeth including the alveolar bone are commonly required. Especially in Endodontics, high resolution images are a requirement that is obtained with small FOVs (7). This has particular importance, because it restricts the area of direct exposure to ROI, possibly reducing the radiation dose to the patient (8-10). However, as the device spins around the patient's head during scanning examination, tissues and structures outside the FOV are also irradiated.

Strikingly, the ratio of dose reduction to these peripheral structures has not yet been established. One factor contributing to this is that most of dosimetry CBCT studies evaluated the dose in exams obtained with large or medium FOVs $(4,10-15)$. In such cases, the large FOV is centered on the maxillo-mandibular region. Therefore, the investigation on small FOVs and the influence of their positioning in relation to critical organs of the head and neck are still poorly explored in the scientific literature.

As known, the need to evaluate specific small areas is frequent in several fields of Dentistry, evidencing the need for comparative studies between absorbed doses in a single 
acquisition of large FOV and multiple acquisitions of small FOVs restricted to ROIs. In addition to teeth and alveolar bone regions, exams with small FOVs may be required to assess the temporomandibular joint (TMJ). However, it is unclear whether the use of a smaller FOV reduces radiation dose to patient, since two exposures would be necessary to scan both TMJs. A direct comparison of doses delivered by different FOV sizes for assessment of bilateral structures has not been performed yet, since previous studies compared doses delivered for TMJ exams produced by different devices $(15,16)$. That drawback was secondary to the use of equipment without large FOV settings; since the devices operated with different energy factors, therefore it is not precise to attribute any dose variation to FOV size alone.

The options of commercially available CBCT units increased substantially and new models are being developed and released. Among them, the OP300 Maxio (Instrumentarium Dental, Tuusula, Finland) stands out for it presents, besides the different scanning modes, the possibility of acquiring images with different FOV sizes, ranging from small to large. Still, dosimetry studies using the small FOVs available in this equipment are relatively scarce (14). Thus, this study aimed to estimate the absorbed dose by the skin surface at sensitive head and neck organs using the varying exposure settings, size and FOV position offered by OP300 Maxio. Additionally, it was also compared the absorbed dose of two smaller FOV scans with the one of a larger FOV scan for TMJ, which has to evaluate both right and left sides.

\section{Material and Methods}

For present study was used a OP300 Maxio CBCT unit (Instrumentarium Dental, Tuusula, Finland), which has a pulsed radiation beam and factors such as voxel size, number of basis images (frames), kilovoltage (kV), milliamperes $(\mathrm{mA})$ and exposure time set automatically according to the scanning mode (standard, high and endo). Tables 1 and 2 show the technical parameters, the FOVs and the ROIs evaluated in this study for maxillofacial and TMJ regions, respectively.

The absorbed dose of the skin surface on sensitive organs was estimated with thermoluminescent dosimeters (TLD-100, LiF: Mg, Ti), which were calibrated before the exposures. For the exposures, an anthropomorphic phantom (711-HN model, Atom
Max dental \& diagnostic head phantom, Computerized Imaging Reference Systems, Inc. - CIRS, Norfolk, VA, USA) was positioned with the occlusal plane parallel to the horizontal plane and the sagittal plane perpendicular to this horizontal plane (Fig. 1A). Three dosimeters were displayed over the following predetermined locations: thyroid gland, parotid gland, submandibular gland and lens eyes, the last three being bilateral (Fig. 1B). A set of dosimeters was placed outside the examination room to measure the average dose of background radiation that should be subtracted from the absorbed dose values.

Due to the relatively low dose of radiation released by a single CBCT scan and to the fact that more dosimeters were outside the primary exposure field when small FOVs were used, two exposures were performed for each protocol without moving the phantom to achieve measurable values even for small radiation doses.

The reading of the dosimeters was conducted after the exposures with a thermoluminescent reader (model 2800, Victoreen, Inc., Cleveland, Ohio, USA). All values were subtracted from those related to background radiation and
Table 1. Exposure protocols and settings used for image acquisition in the dentomaxillofacial region

\begin{tabular}{|c|c|c|c|}
\hline Scanning mode & Spatial resolution & $\mathrm{FOV}(\mathrm{cm})$ & ROI \\
\hline \multirow[t]{2}{*}{$\begin{array}{l}\text { Standard } \\
(8.0 \mathrm{~mA} ; 90 \mathrm{kVp} ; \\
\left.\mathrm{t}=2.3 \mathrm{~s} ; \operatorname{spin}=270^{\circ}\right)\end{array}$} & \multirow[t]{2}{*}{$\begin{array}{l}\text { Voxel size: } 0.2 \mathrm{~mm} \text {; } \\
\text { Frames: } 234^{*}\end{array}$} & $5 \times 5^{* *}$ & $\begin{array}{l}\text { Anterior maxilla**** } \\
\text { Posterior maxilla**** } \\
\text { Anterior mandible**** } \\
\text { Posterior mandible }\end{array}$ \\
\hline & & $8 \times 15^{* * *}$ & Maxilla and Mandible ${ }^{* * * *}$ \\
\hline $\begin{array}{l}\text { High } \\
(6.3 \mathrm{~mA} ; 90 \mathrm{kVp} ; \\
\left.\text { t=6.1s; } \mathrm{Spin}=270^{\circ}\right)\end{array}$ & $\begin{array}{l}\text { Voxel size: } 0.125 \mathrm{~mm} \text {; } \\
\text { Frames: } 609^{*}\end{array}$ & $5 \times 5$ & $\begin{array}{l}\text { Anterior maxilla**** } \\
\text { Posterior maxilla**** } \\
\text { Anterior mandible**** } \\
\text { Posterior mandible }{ }^{* * * *}\end{array}$ \\
\hline $\begin{array}{l}\text { Endo } \\
(6.3 \mathrm{~mA} ; 90 \mathrm{kVp} ; \\
\left.\mathrm{t}=8.7 \mathrm{~s} ; \mathrm{Spin}=270^{\circ}\right)\end{array}$ & $\begin{array}{l}\text { Voxel size: } 0.085 \mathrm{~mm} \text {; } \\
\quad \text { Frames }=870^{*}\end{array}$ & $5 \times 5$ & $\begin{array}{l}\text { Anterior maxilla } a^{* * * *} \\
\text { Posterior maxilla****} \\
\text { Anterior mandible } \\
\text { Posterior mandible***** }\end{array}$ \\
\hline
\end{tabular}

FOV: field of view. ROI: region of interest. Compares *the effect of different protocols of voxel size and frames on dose, ${ }^{* *}$ the effect of FOV size on dose, ${ }^{* * *}$ the effect of FOV positioning on dose.
Table 2. Exposure protocols and settings used for image acquisition in the TMJ region

\begin{tabular}{lccc}
\hline Scanning mode & Spatial resolution & FOV & ROI \\
\hline Standard & Voxel size: $0.2 \mathrm{~mm} ;$ & $5 \times 5^{*}$ & TMJ (one side) \\
$(8.0 \mathrm{~mA} ;$ 90kVp; & Frames $=234$ & $8 \times 15^{*}$ & TMJ (one side)** \\
$\mathrm{t}=2.3 \mathrm{~s} ;$ spin $\left.=270^{\circ}\right)$ & & 8 (bilaterally) & \\
\hline
\end{tabular}

FOV: field of view. ROI: region of interest. Compares *the effect of FOV size on dose, **the absorbed dose of one scan for both TMJs with two smaller FOVs (one for each TMJ). 
divided by the number of exposures (two) to express the average exposure per dosimeter. Then, the mean value for each pair of dosimeters was obtained and represented the absorbed dose for each region. Doses of all regions were then added to obtain the final absorbed dose for each exam. Exposures were recorded in nanocoulombs $(\mathrm{nC})$ and then converted to express the dosimetric data in miligrays (mGy).

Statistical analysis was performed using SPSS version 22.0 (SPSS Inc., Chicago, IL, USA). Two-way analysis of variance (ANOVA) with the Tukey's post-hoc test was used to assess the effect of scanning modes and FOV position and size on dose when a $5 \times 5 \mathrm{~cm}$ FOV was used. One-way ANOVA with the post-hoc Tukey test was employed to evaluate the influence of FOV size on dose for dentomaxillofacial and TMJ scans. A significance level of 5\% was set for all analyses.

\section{Results}

Figure 2 shows the total doses absorbed with the $5.0 \times 5.0 \mathrm{~cm}$ FOV aimed to different positions and using the three available scanning modes. In Table 3, are shown the
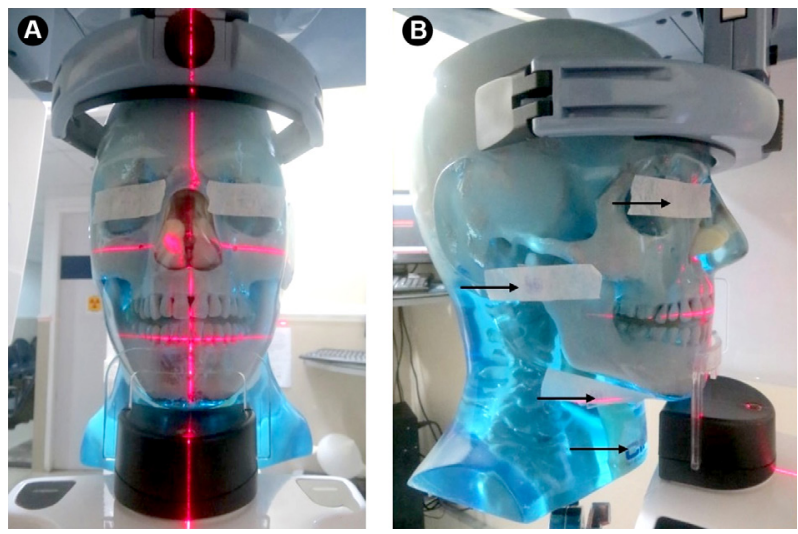

Figure 1. Phantom positioning in the OP300 Maxio unit (A) showing the thermoluminescent dosimeters in the predetermined locations (arrows) (B). absorbed doses by the skin surface at each sensitive organ. In the standard mode, parotid and submandibular glands were, respectively, the regions most exposed in maxilla and mandible examinations, while in the other scanning modes the thyroid gland showed the highest absorbed dose, both in maxillary and mandibular acquisitions. On the other hand, the total absorbed dose, which represents the sum of dosimeter averages of the seven locations, showed that anterior maxilla had lower values compared to posterior maxilla, as did the anterior mandible in relation to posterior mandible (Fig. 2). In the same scanning mode, the absorbed doses in anterior regions did not differ significantly from each other $(p=0.113)$, but differed from those of the posterior regions $(p<0.0001)$. The posterior mandible showed the highest values in all protocols, which differed from the others. When the FOV was changed from anterior to posterior region in the standard, high and endo modes, respectively, there was an increase of $16 \%, 28 \%$ and $62 \%$ of the total absorbed dose for maxilla acquisitions and $76 \%, 100 \%$ and $112 \%$ for mandible acquisitions.

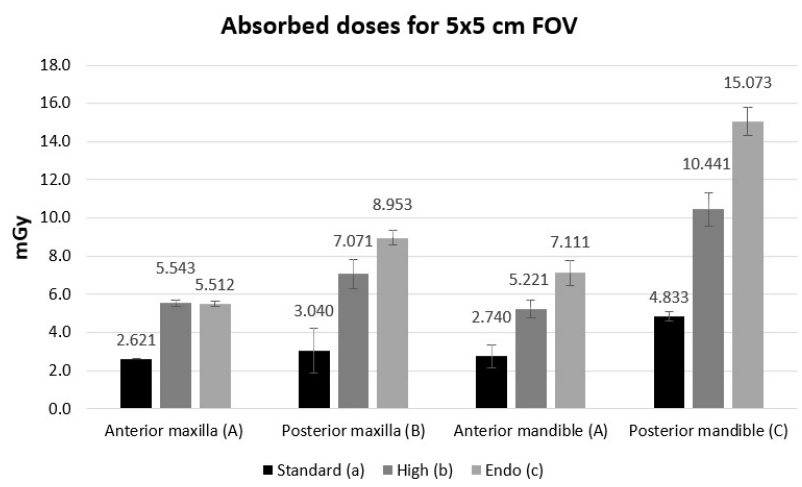

Figure 2. Estimates for total absorbed doses (mGy) by the skin surface at sensitive organs according to the different scanning modes with the $5 \times 5 \mathrm{~cm}$ FOV (field of view). Different capital letters indicate statistically significant difference between regions; different lower letters indicate difference between scanning modes, according to ANOVA.

Table 3. Absorbed doses (mGy) of skin surface at sensitive organs for FOV of 5 x $5 \mathrm{~cm}$ according to the different scanning modes and FOV position

\begin{tabular}{|c|c|c|c|c|c|c|c|c|c|c|c|c|}
\hline \multirow{3}{*}{ Organ } & \multicolumn{12}{|c|}{ Scanning sode } \\
\hline & \multicolumn{4}{|c|}{ Standard } & \multicolumn{4}{|c|}{ High } & \multicolumn{4}{|c|}{ Endo } \\
\hline & $\begin{array}{c}\text { Anterior } \\
\text { Maxilla }\end{array}$ & $\begin{array}{c}\text { Posterior } \\
\text { Maxilla }\end{array}$ & $\begin{array}{c}\text { Anterior } \\
\text { Mandible }\end{array}$ & $\begin{array}{l}\text { Posterior } \\
\text { Mandible }\end{array}$ & $\begin{array}{l}\text { Anterior } \\
\text { Maxilla }\end{array}$ & $\begin{array}{c}\text { Posterior } \\
\text { Maxilla }\end{array}$ & $\begin{array}{c}\text { Anterior } \\
\text { Mandible }\end{array}$ & $\begin{array}{l}\text { Posterior } \\
\text { Mandible }\end{array}$ & $\begin{array}{l}\text { Anterior } \\
\text { Maxilla }\end{array}$ & $\begin{array}{c}\text { Posterior } \\
\text { Maxilla }\end{array}$ & $\begin{array}{c}\text { Anterior } \\
\text { Mandible }\end{array}$ & $\begin{array}{l}\text { Posterior } \\
\text { Mandible }\end{array}$ \\
\hline $\begin{array}{l}\text { Lens of } \\
\text { the eye } \neq\end{array}$ & 0.175 & 0.161 & 0.019 & 0.026 & 0.410 & 0.339 & 0.080 & 0.077 & 0.560 & 0.501 & 0.122 & 0.129 \\
\hline Parotid gland $\ddagger$ & 2.280 & 2.626 & 0.071 & 0.123 & 4.779 & 6.148 & 0.179 & 0.284 & 4.473 & 7.718 & 0.273 & 0.433 \\
\hline $\begin{array}{l}\text { Submandibular } \\
\text { gland } \neq\end{array}$ & 0.141 & 0.227 & 2.533 & 4.512 & 0.281 & 0.507 & 4.753 & 9.723 & 0.391 & 0.639 & 6.368 & 13.983 \\
\hline Thyroid gland & 0.025 & 0.025 & 0.117 & 0.172 & 5.543 & 7.071 & 5.221 & 10.441 & 5.512 & 8.953 & 7.111 & 15.073 \\
\hline
\end{tabular}

FOV: field of view. $¥$ Sum of 2 dosimeter runs. 
Furthermore, the scanning modes and spatial resolution changes (standard $x$ high $x$ endo) caused an increase in the total absorbed dose, which in some cases was over 100\%. The increase was more pronounced when the standard and endo modes were compared. The differences among the scanning modes were statistically significant according to ANOVA $(p<0.0001)$.

Absorbed doses according to standard mode and different FOV sizes are shown in Figure 3. A dose reduction occurred when small FOVs were used $(p=0.001)$, but it was not proportional to the reduction of the scanned area. In fact, while the area was reduced 5 times, the dose decreased 2.5 times on average.

Figure 4 shows the absorbed doses related to CBCT acquisition with Standard mode and different FOV sizes $(5 \times 5$ $\mathrm{cm}, 6 \times 8 \mathrm{~cm}$ and $8 \times 15 \mathrm{~cm}$ ) for the TMJ region. The $5 \times 5 \mathrm{~cm}$ and $6 \times 8 \mathrm{~cm}$ FOV values represent duplicate readings to estimate a bilateral TMJ exam (absorbed dose of one exam with $5 \times 5$

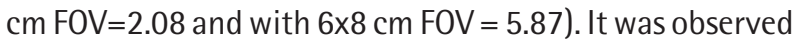
that parotid glands were the regions that contributed most to the total absorbed dose in TMJ acquisitions, while the thyroid gland had the lowest absorbed dose measurements.

$\overrightarrow{5}$ Two exams with a smaller FOV $(5 \times 5 \mathrm{~cm})$ resulted in less than half of the total absorbed dose of one scan with a greater FOV. On the other hand, acquisition of two exams with the medium-sized FOV $(6 \times 8 \mathrm{~cm})$ resulted in a larger dose than the one obtained with a single greater FOV. ANOVA showed statistically significant differences between the values related to TMJ $(p=0.001)$. Considering the cases in which double exposures are performed (open and closed mouth positions), which represent the most common TMJ acquisition protocol, the differences between the absorbed doses also doubled.

\section{Discussion}

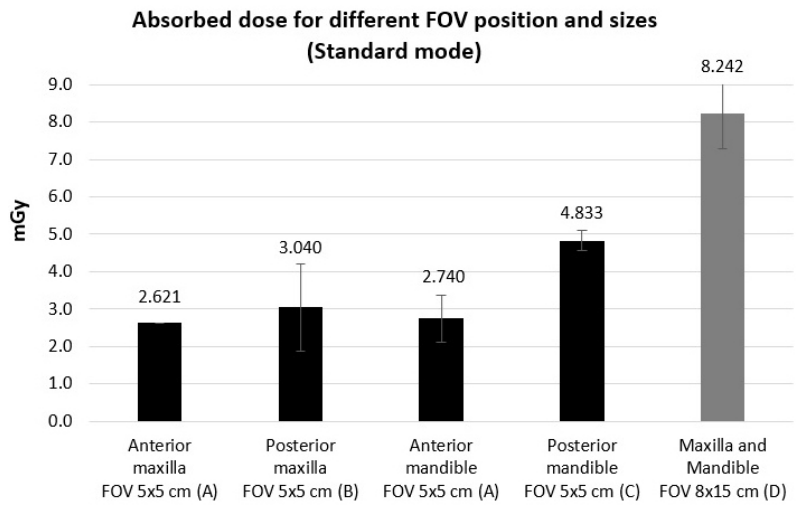

Figure 3. Estimates for the absorbed doses of the skin surfaces at sensitive organs according to the different FOV (field of view) position and sizes, in the Sdtandard mode (mGy). Different letters indicate statistically different values, according to ANOVA.
Over the past decade, $\mathrm{CBCT}$ imaging gained popularity among dental professionals. At the same time, its use has raised the level of concern regarding the exposure of patients to radiation. Pioneering studies on CBCT dosimetry have used FOVs considered medium or large centered in the maxilla and mandible of anthropomorphic phantoms $(8,17-19)$. As CBCT units began to offer smaller FOVs, two questions derived from such innovation: how does FOV reduction and FOV positioning affect an exam's total radiation dose? Therefore, in this study, a device that is not only relatively new on the market but also allows the choice of varied FOV sizes from small to large, was tested to enable the proposed comparisons.

The absorbed doses obtained in this study are difficult to evaluate against those from previous researches, since the differences in the used equipment, FOV positioning, technical settings, and dosimetry methods employed make any attempt of comparison a challenge. Regarding the sites where the dosimeters were placed to measure absorbed doses, the International Commission of Radiological Protection (ICRP) points out that salivary glands and thyroid are at risk of stochastic effects related to radiation exposure, and therefore they were included in the calculation of the effective dose (20). The lens of the eye is also a cause of concern in relation to effects induced by ionizing radiation, such as lens opacification and cataracts $(20,21)$. Besides that, these are some of the most exposed tissues during the $\mathrm{CBCT}$ dental examinations.

Only one dosimetry study using OP300 Maxio was found in literature, witch assessed the effective dose in CBCT scans with different FOVs located in the maxilla and mandible regions (14). Similar to the present results, the authors showed decrease in dose when small FOVs were used. However, this prior study did not vary the small FOVs

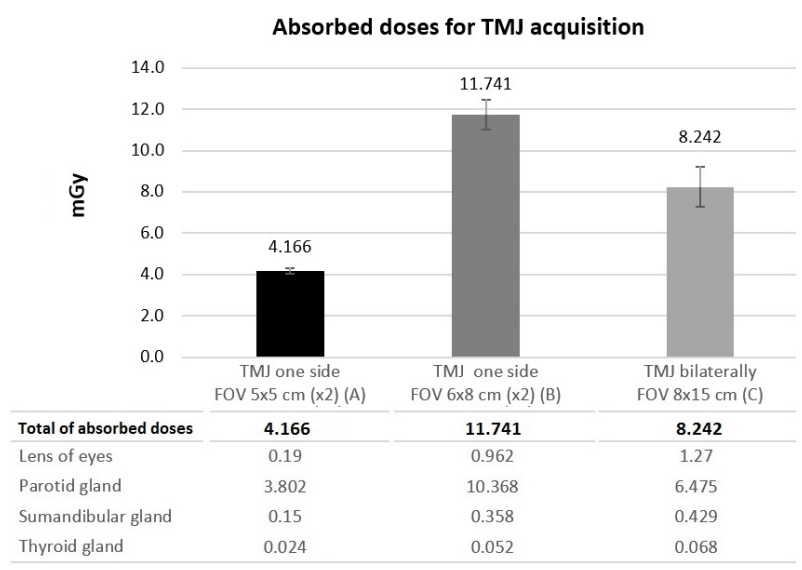

Figure 4. Estimates for the absorbed doses of the skin surface at sensitive organs according to the different FOV (field of view) sizes using the Standard mode for the TMJ (mGy). Different letters indicate statistically different values, according to ANOVA. 
position in relation to the anterior and posterior regions of the maxilla and mandible; it used a larger FOV $(13 \times 15$ $\mathrm{cm})$ than the ones in the present study $(8 \times 15 \mathrm{~cm})$ and not performing dosimetry tests for TMJ (14).

In the present study, it was possible to verify the effect of exposure parameters and small FOVs positioning in the absorbed dose on the skin surface at specific organs. There was a progressive increase in dose for all FOV positions with the standard, the high and the endo modes, respectively. In the studied CBCT device, there is an automatic adjustment of the acquisition parameters according to the selection of the scanning modes. While the standard mode was set with higher $m A$, exposure time went up three to four times in the high and endo modes, respectively. An increase of the spatial resolution (smaller voxel size and higher number of base images) from the standard mode to high, followed by endo is also related to that and contributes to the dose increase. The only exception to this trend was in the anterior maxilla, which could be explained due to the greater distance from the evaluated organs and to the fact that the device does not rotate fully around the patient's head.

It is essential that an ideal FOV be selected for each patient, according to the clinical needs or the evaluated anatomical region (8). In all protocols with the small FOV $(5 \times 5 \mathrm{~cm})$, there was a trend of increasing doses as the FOV was moved from anterior to posterior. A possible explanation for that finding is that the posterior regions presented comparatively more radiosensitive structures directly exposed to the primary radiation beam.

In this study, there were reductions in the absorbed dose when limiting the FOV to the ROI. However, dose reduction is not proportional to the reduction of the scanned area. Thus, it must be noted that if the patient requires evaluation of all the maxilla and mandible, a large, $8 \times 15 \mathrm{~cm}$ FOV is recommended, since the total absorbed dose with such FOV is comparatively lower. It is important to consider that using a small FOV solely does not ensure a lower absorbed dose to the patient. In fact, other factors contribute to the final dose, such as acquisition protocols and number of base images. Here, the doses obtained by using the small FOV in the posterior regions with the high and endo modes were similar or even higher than those measured when using the large FOV with the standard mode.

On the other hand, the results obtained for the TMJ scans demonstrated that the restriction of the FOV to the ROI (i.e., using a smaller FOV for each joint) decreased the absorbed dose when compared to a larger FOV that captures both TMJs. Similarly, Luckat et al. (15) performed dosimetry of CBCT exams for TMJ region and reported a significant reduction of effective dose when two small FOVs were used in comparison with a large FOV. However, different CBCT devices were used for this purpose: Kodak
9000 for image acquisitions with small FOV and Hitachi CB MercuRay for a single field acquisition including both TMJs. Alternatively, another study showed that the doses absorbed by the lens of the eye were not reduced when a limited FOV for the TMJ was used. These authors also used different devices (CS 9000, Gendex GXCB 500 and i-CAT classic) to obtain different FOVs (16). Comparing the results obtained with different CBCT units creates a bias because factors that differ from one unit to the other, such as energy parameters, may affect the radiation dose. In this study, it was able to isolate FOV size as the independent variable to assess its actual influence.

In addition, a medium-sized FOV was used for examining the TMJs, because a small FOV might not cover the entire region of interest and adjacent structures, especially when the patient's mouth is open. Therefore, some professionals would prefer a $6 \times 8 \mathrm{~cm}$ FOV. However, two scans with the medium-sized FOV (one for each TMJ) showed higher absorbed doses compared to one scan performed with a greater FOV, which involved both TMJs. In this particular case, FOV reduction did not produce an effective reduction in total absorbed dose, suggesting that a greater FOV is beneficial when imaging bilateral structures such as the TMJs. It must be emphasized that using smaller FOVs does not ensure lower absorbed doses to the patient and the professional should know dose values delivered by different protocols and evaluate case by case. Additionally, the authors also stress that choice of FOV size for TMJ exams is especially relevant because dose differences are maximized by the number of acquisitions in the case of functional examinations (open and closed mouth).

This study is important to highlight the influence of exposure factors, size and FOV location on the dose absorbed by patient. However, further researches involving dosimetry in CBCT exams and associating the results with image quality and its application in specific diagnostic tasks are also required for professional decision-making while choosing how the examination should be performed. Despite the fact that CBCT provides low radiation doses, it is imperative to know the dose levels as well as the strategies for dose reduction with different CBCT units and operating modes, since the damaging potential of X-ray use is cumulative (22).

In conclusion, scanning mode, size and FOV position have great influence on absorbed dose values. When a small FOV was used, lower adsorbed doses were found for "Standard" scanning mode and for anterior regions. Small FOV decreased the absorbed dose, but FOV size and absorbed dose are not proportional. In addition, although smaller FOV showed a trend to reducing absorbed doses, this is relative to its size and location, and acquisition parameters. For bilateral structures as TMJ, double acquisition with 
small FOV is recommended, since it represents a decrease in adsorbed dose relative to a large FOV, but this was not observed using two acquisitions with a medium-sized FOV.

\section{Resumo}

0 objetivo deste estudo foi estimar a dose absorvida em exames de tomografia computorizada de feixe cônico (TCFC) de acordo com diferentes parâmetros de exposição, tamanho e posição do campo de visão (FOV, do inglês field of view). Além disso, comparou-se a dose absorvida em uma única aquisição com FOV grande com aquela em duas aquisições com FOVs menores para avaliação de estruturas bilaterais como a articulação temporomandibular (ATM). As aquisições de TCFC foram obtidas no aparelho OP300 Maxio, variando o modo de aquisição (standard, high e endo), bem como o tamanho $(5 \times 5,6 \times 8$ e $8 \times 15 \mathrm{~cm})$ e o posicionamento do FOV. Com o FOV pequeno, foram escaneadas diferentes áreas (maxila ou mandibula, anterior ou posterior e ATM). As doses absorvidas foram determinadas por meio da utilização de dosimetros termoluminescentes na superfície da pele em órgãos sensiveis de um phantom antropomórfico. 0 modo endo mostrou a dose mais alta, seguido pelos modos high e standard em todas as posições dos FOVs. Com um FOV pequeno, as doses foram maiores na região posterior, especialmente na mandibula. A redução da dose ocorreu quando foram utilizados pequenos FOVs; contudo, essa redução não foi proporcional à redução do tamanho do FOV. Para a ATM, a dose em uma única aquisição com FOV grande foi maior que duas aquisições com FOV pequeno, porém inferior à dose de duas aquisições com FOV médio ( $6 \times 8 \mathrm{~cm})$. Em conclusão, o modo de aquisição, o tamanho e a posição do FOV têm grande influência na dose absorvida. FOVs pequenos apresentaram doses mais baixas em relação aos FOVs grandes, entretanto não há uma relação linear entre o tamanho do FOV e a dose absorvida. Para estruturas bilaterais como a ATM, a dupla aquisição com FOV pequeno representa uma diminuição na dose absorvida em relação a uma aquisição com FOV grande.

\section{Acknowledgements}

The authors would like to thank the Coordination for the Improvement of Higher Education Personnel (CAPES) for the financial support.

\section{References}

1. Mozzo P, Procacci C, Tacconi A, Martini PT, Andreis IA. A new volumetric $\mathrm{CT}$ machine for dental imaging based on the cone-beam technique: preliminary results. Eur Radiol 1998;8:1558-1564.

2. Arai $Y$, Tammisalo E, Iwai K, Hashimoto K, Shinoda K. Development of a compact computed tomographic apparatus for dental use. Dentomaxillofac Radiol. 1999;28:245-248.

3. Pauwels R. Cone beam CT for dental and maxillofacial imaging: dose matters. Radiat Prot Dosimetry 2015;165:156-161.

4. Andrade ME, Khoury HJ, Nascimento Neto JB, Kramer R. Dosimetric evaluation of dental implant planning examinations with cone-beam computed tomography. Radiat Prot Dosimetry 2014;158:175-180.

5. SEDENTEXCT guidelines. Safety and efficacy of a new and emerging dental X-ray modality. Radiation protection no. 172: cone beam CT for dental and maxillofacial radiology. Evidence based guidelines. Geneva, Switzerland: European Commission 2012. Available at: http://www. sedentexct.eu/files/radiation_protection_172.pdf

6. Jaju PP, Jaju SP. Cone-beam computed tomography: Time to move from
ALARA to ALADA. Imaging Sci Dent 2015:45:263-265.

7. Dula $K$, Benic Gl, Bornstein M, Dagassan-Berndt D, Filippi A, Hicklin $\mathrm{S}$, et al.. SADMFR Guidelines for the Use of Cone-Beam Computed Tomography/Digital Volume Tomography. Swiss Dent J 2015;125:945953.

8. Davies J, Johnson B, Drage N. Effective doses from cone beam CT investigation of the jaws. Dentomaxillofac Radiol 2012;41:30-36.

9. Ludlow JB, Walker C. Assessment of phantom dosimetry and image quality of i-CAT FLX cone-beam computed tomography. Am J Orthod Dentofacial Orthop 2013;144:802-817.

10. Bornstein MM, Scarfe WC, Vaughn VM, Jacobs R. Cone beam computed tomography in implant dentistry: a systematic review focusing on guidelines, indications, and radiation dose risks. Int J Oral Maxillofac Implants 2014;29:55-77.

11. Olszewski R, Frison L, Wisniewski M, Denis JM, Vynckier S, Cosnard G, et al.. Reproducibility of three-dimensional cephalometric landmarks in cone-beam and low-dose computed tomography. Clin Oral Investig 2013;17:285-292.

12. Hofmann E, Schmid M, Sedlmair M, Banckwitz R, Hirschfelder U, Lell M. Comparative study of image quality and radiation dose of cone beam and low-dose multislice computed tomography-an in-vitro investigation. Clin Oral Investig 2014;18:301-311.

13. Khoury HJ, Andrade ME, Araujo MW, Brasileiro IV, Kramer R, Huda A. Dosimetric study of mandible examinations performed with three cone-beam computed tomography scanners. Radiat Prot Dosimetry 2015; 165:162-165

14. Ludlow JB, Timothy R, Walker C, Hunter R, Benavides E, Samuelson $\mathrm{DB}$, et al.. Effective dose of dental CBCT-a meta analysis of published data and additional data for nine CBCT units. Dentomaxillofac Radiol 2015:44:20140197.

15. Lukat TD, Wong JC, Lam EW. Small field of view cone beam CT temporomandibular joint imaging dosimetry. Dentomaxillofac Radiol 2013:42:20130082

16. Oliveira MVL, Andrade MEA, Batista WO, Campos PSF. Skin doses on the lens for temporomandibular joint exam in cone beam computed tomography. Braz. Arch Biol Technol 2015;58:886-890.

17. Ludlow JB, Davies-Ludlow LE, Brooks SL. Dosimetry of two extraoral direct digital imaging devices: NewTom cone beam CT and Orthophos Plus DS panoramic unit. Dentomaxillofac Radiol 2003;32:229-234.

18. Ludlow JB, Ivanovic M. Comparative dosimetry of dental CBCT devices and 64-slice CT for oral and maxillofacial radiology. Oral Surg Oral Med Oral Pathol Oral Radiol Endod 2008;106:106-114.

19. Qu XM, Li G, Ludlow JB, Zhang ZY, Ma XC. Effective radiation dose of ProMax 3D cone-beam computerized tomography scanner with different dental protocols. Oral Surg Oral Med Oral Pathol Oral Radiol Endod 2010;110:770-776

20. ICRP. Statement on Tissue Reactions. International Commission on Radiological Protection, 2011

21. ICRP. The 2007 Recommendations of the International Commission on Radiological Protection: ICRP Publication 103. Annals of the ICRP 2007:37:1-332.

22. Ali AS, Fteita D, Kulmala J. Comparison of physical quality assurance between Scanora 3D and 3D Accuitomo 80 dental CT scanners. Libyan J Med 2015;18:28038
Received February 6, 2017 Accepted May 22, 2017 